Bond University ePublications@bond

Sports Law eJournal

Faculty of Law

12-1-2012

\title{
Contador, cows and strict liability
}

Saul Fridman

University of Sydney

Follow this and additional works at: http://epublications.bond.edu.au/slej

Part of the Sports Sciences Commons

\section{Recommended Citation}

Saul Fridman. (2012) "Contador, cows and strict liability" Sports Law eJournal, : ISSN 1836-1129.

http://epublications.bond.edu.au/slej/16

This Journal Article is brought to you by the Faculty of Law at ePublications@bond. It has been accepted for inclusion in Sports Law eJournal by an authorized administrator of ePublications@bond. For more information, please contact Bond University's Repository Coordinator. 


\title{
Contador, cows and strict liability
}

\begin{abstract}
Extract:

The fight to eradicate the use of performance enhancing substances in sport has been the matter of significant public attention in recent years. Perhaps no sport is affected more than the sport of cycling.
\end{abstract}

\section{Keywords}

doping in sport, strict liability, cycling and doping, WADA, World Anti-Doping Code, Contador, no significant fault

\section{Disciplines}

Sports Sciences 
Fridman: Contador, cows and strict liability

\title{
CONTADOR, COWS AND STRICT LIABILITY
}

\author{
SAUL FRIDMAN 1
}

The fight to eradicate the use of performance enhancing substances in sport has been the matter of significant public attention in recent years. Perhaps no sport is affected more than the sport of cycling.

Many consider the genesis for the development of sophisticated modern anti-doping rules was the televised death of British cyclist, Tommy Simpson, in the 1967 Tour de France. It was in that year that the International Olympic Committee established its own anti-doping code. ${ }^{2}$ Over the next three decades, the fight against doping in sport has been one of the principal themes in international sports law.

In 1999, the International Olympic Committee established the World Anti-Doping Agency ('WADA'). This move was seen as essential to ensure the application of consistent, harmonized and appropriate approaches to the anti-doping efforts. As part of these anti-doping efforts, WADA developed and enforced a principle of strict liability incorporated in anti-doping rules introduced in 2003. The decision of the Court of Arbitration for Sport ('CAS') in Contador ${ }^{3}$ is but the latest in a line of cases where athletes have attempted to claim the absence of fault (or significant fault) where a prohibited substance has been found in their system. This case is an excellent example of the lengths to which this principle is now taken, and the efforts required for an athlete to prove such claims.

\section{The principle of strict liability in doping cases}

The strict liability principle requires that an athlete be found to have committed an anti-doping violation in any case where a prohibited substance is found to be present in the athlete's system. Athletes are required to submit to in-competition and out-of-competition blood and urine testing, with samples analysed by WADA-accredited laboratories. ${ }^{4}$ A period of ineligibility of 2 years would be imposed for a first offence and a lifetime ban for a subsequent offence (for prohibited substances). ${ }^{5}$

1 Associate Professor, Faculty of Law, University of Sydney.

2 The history of efforts to establish a workable anti-doping code is well discussed in D Thorpe et al, Sports Law (Oxford University Press, 2009) 171-180.

3 UCI v Alberto Contador Velasco E RFEC; WADA v Alberto Contador Velasco E RFEC (CAS 2011/A/2384; CAS 2011/A/2386, 6 February 2012), available online at: http://www.tascas.org/d2wfiles/document/5648/5048/0/FINAL20AWARD202012.02.06.pdf ('Contador award').

4 See article 2.1, World Anti-Doping Code, available online at: http://www.wada-ama.org/World-AntiDoping-Program/Sports-and-Anti-Doping-Organizations/The-Code/ ('World Anti-Doping Code').

5 Article 10.2, World Anti-Doping Code. 


\section{CONTADOR, DOPING AND STRICT LIABILITY}

In 2007, the provisions of the WADC were substantially revised, partly to ensure that the application of the strict liability standard was proportionate and fair to all concerned. These revisions clarified the position of an athlete who claimed to have been the victim of 'inadvertent doping', that is to say where test results reveal evidence of a prohibited substance or method in circumstances of mistake or genetic susceptibility where there is no intent to enhance performance. Sanctions could be mitigated by demonstrating that the athlete was not at fault (or not at significant fault), ${ }^{6}$ or that he or she 'did not intend to enhance his or her sport performance'. ${ }^{7}$ These provisions, allowing the athlete to escape sanction in certain circumstances, arguably offset any seeming unfairness to the athlete. ${ }^{8}$

There have been concerns voiced about such possible unfairness. Some assert that this is contrary to principles of natural justice ${ }^{9}$ and others have expressed concern that this standard is in violation of norms of international human rights law. ${ }^{10}$ With respect to the latter, the basic argument is that culpability ought to require proof of subjective blameworthiness, yet the strict liability principle does not. Additionally, uniform sanctions for anti-doping violations violate the international standard requiring sanctions to be 'proportionate' to the wrong; a fixed two-year sanction for a 'first offence' is arguably inconsistent with this norm.

In response to these concerns, WADA sought a legal opinion on the compliance of the World Anti-Doping Code with international human rights norms. A panel of three experts found that both the principle of strict liability and automatic disqualification comply with international human rights standards, because the potential fault or negligence of the athlete is still considered with the possibility of reduced sanctions. ${ }^{11}$ The application of this principle does appear to

6 Article 10.5, World Anti-Doping Code.

7 Article 10.4, World Anti-Doping Code.

8 The critical provisions are contained in Article 10.5 of the World Anti-Doping Code, which provides for the athlete to escape sanction either wholly or in part by establishing the absence of fault or negligence in the circumstances leading to the presence of the prohibited substance in his or her system. Even though there may be no sanction, the rules clearly state that the athlete forfeits any result in the competition where he or she might have been affected.

9 Paul McCutcheon, 'Sports Discipline, Natural Justice and Strict Liability' (1999) 28 Anglo American Law Review 37; Antonio Buti and Saul Fridman, 'Drug Testing in Sport; Legal Challenges and Issues' (1999) 20(2) University of Queensland Law Journal 153.

10 See the expressed views of the CAS panel in Jessica Foschi v FINA (CAS 1996/156), available online at: http://www.chapmanandintrieri.com/assets/files/News and Publications/Sports AAA Opinions/Foschi \%20CAS1.pdf, p 41-42; see also comments made in respect of proportionality of sanctions in Richard $\mathrm{H}$ McLaren, 'A New Order: Athletes' Rights and the Court of Arbitration at the Olympic Games' (1998) 8 OLYMPICA: The International Journal of Olympic Studies 1, 16.

11 See Prof G Kaufmann-Kohler, Prof G Malinverni, and A Rigozzi, 'Legal Opinion on the Conformity of Certain Provisions of the Draft World Anti-Doping Code with Commonly Accepted Principles of International Law, February 2003, available online at: http://www.wada-ama.org/en/World-AntiDoping-Program/Legal-articles-case-law-and-national-laws/Advisory-and-Legal-Opinions-on-theCode/. 
demonstrate a degree of unfairness in individual cases, ${ }^{12}$ but the approach taken by WADA is consistent, and the CAS routinely accepted the necessity of strict liability. ${ }^{13}$ While concerns have been expressed about whether the provisions go far enough, ${ }^{14}$ there appears (at least at this stage) to be general acceptance of the appropriateness of the strict liability standard. Therefore, in cases where the athlete wishes to challenge the imposition of a sanction for a doping violation, the trend has been for the athlete to argue that he or she bears either no fault or no significant fault for the substance in question being present in his or her system.

\section{Claiming no fault or no significant fault}

Indeed, there have been a number of CAS decisions involving athletes making claims that they were not at fault, or not at significant fault, in causing a prohibited substance to enter their system. ${ }^{15}$ (It is important to note that the rules provide very clearly that where an athlete wishes to make use of the sanction-reducing provisions, there must be admission of the presence of the substance in their system. Thus, athletes wishing to make these arguments are well advised not to challenge the testing protocols or the custody of the evidence.) $)^{16}$

12 See, eg, Alain Baxter v IOC (CAS 2002/A/376, 15 October 2002), available online at: http://jurisprudence.tas-cas.org/sites/CaseLaw/Shared\%20Documents/376.pdf where a British athlete, while competing in the Salt Lake City Olympic Games, used an over the counter medication unaware that the local preparation of the relevant product (marketed in the US under the same brand name as in the UK) contained a banned stimulant. The athlete's lack of awareness did not prevent a finding that he had contravened the relevant anti-doping policy. This result would arguably be different today as a result of the insertion into the WADC in 2007 of new provisions dealing with substances that are more likely to be ingested in this manner (specified substances), see Article 10.4, World Anti-Doping Code.

13 See below.

14 Professor Richard McLaren, a prominent CAS arbitrator has made suggestions to this effect: see Richard H McLaren, 'CAS Doping Jurisprudence: What Can We Learn?' (2006) International Sports Law Review 4. McLaren refers to comments made by the CAS panel in G Squizzato v FINA (CAS 2005/A/830, 15 July 2005). The suggestion is made in both the CAS decision and McLaren's article that Article 10.5 unduly restricts the discretion of the CAS (or any other relevant panel) when dealing with cases of 'inadvertent' doping.

15 See, eg, Andreea Raducan v IOC (CAS ad hoc Division OG 00/011, 28 September 2000), available online at: http://jurisprudence.tas-cas.org/sites/CaseLaw/Shared\%20Documents/OG\%2000-011.pdf; ITF v Richard Gasquet (CAS 2009/A/1926) and WADA v Gasquet (CAS 2009/A/1930, 17 December 2009), available online at: http://jurisprudence.tas-cas.org/sites/CaseLaw/Shared\%20Documents/1926, \%201930.pdf .

Such as, eg, the approach taken by Australian sprinter Dean Capobianco, who while successful at first instance, ultimately failed in his defence before the International Association of Athletics Federation ('IAAF') panel: see IAAF, 'IAAF Panel Decides that Capobianco Committed Doping Offence, General News (17 March 1997), available online at: http://www.iaaf.org/news/kind=101/newsid=15798.html (no written reasons were given by the IAAF appeal panel). By contrast, after a long and protracted legal battle, British athlete Dianne Modahl succeeded in demonstrating that the manner in which her sample was treated made it more likely than not that the test results were the product of the sample having become degraded by failing to refrigerate appropriately: see Mike Rowbottom, 'Modahl Wins Her Appeal Against Drug Ban', The Independent (27 July 1995), available online at: http://www.independent.co.uk/news/diane-modahl-wins-her-appeal-against-drugs-ban-1593345.html . 
For example, when American sprinter Tori Edwards was found to have the presence of banned glucocorticosteroid, Nikethamide, in her system, she argued that she was unaware of the presence of the prohibited substance in a commercially available over-the-counter preparation that, in her home country, did not contain it. ${ }^{17}$ Likewise, in Baxter, the athlete, whose submissions were sympathetically received by the anti-doping panel, established that the inhaler he used (Baxter was an asthmatic) was the same brand as he used in his home country and he was unaware that in the United States that brand contained a banned stimulant.

\section{The substance Clenbuterol}

Cases involving the substance Clenbuterol, a steroid listed on the WADA Prohibited List, ${ }^{18}$ often give rise to such claims. Unlike some other substances, Clenbuterol is banned at all times and there is no threshold level under which its presence does not lead to an anti-doping violation. Although many such cases do not end favourably for the athlete, the CAS has reduced sanctions in relation to inadvertent Clenbuterol doping on occasion: for example, swimmer Jessica Hardy was able to prove that her vitamin supplements were tainted with Clenbuterol, and WADA's appeal to increase the suspension period to 2 years from 1 year was dismissed. ${ }^{19}$ Proving such inadvertent doping, however, remains an issue: in the case of Josephine Onyia, the athlete was initially cleared but WADA appealed to the CASE, who were not satisfied by Onyia's claim that the ingestion of meat contaminated with Clenbuterol caused her positive result, as it was not supported by evidence on the balance of probabilities. ${ }^{20}$

\section{Clenbuterol and tainted meat}

The argument that tainted meat caused a positive result for Clenbuterol is often raised by athletes, particularly in places known to use this substance in the livestock industry (like China and Mexico), though few such cases have been heard by the CAS. For example, The World Badminton Federation Doping Hearing Panel banned former World Number 1 player Zhou Mi for two years after an out-of-competition positive for this substance, after she acknowledged she took some Chinese medicine (which may have contained Clenbuterol) without declaring it. Several weeks after the hearing, Zhou Mi gave a press conference indicating that it was not the Chinese medicine but the consumption of pork from China that caused the positive sample, although this was never ruled on by a judicial body and thus could not have been appealed by WADA..$^{21}$ Dimitrij Ovtcharov, a German table tennis champion, returned a positive sample for

17 Tori Edwards v IAAF and USATF (CAS ad hoc Division OG 04/003).

18 WADA, 'List of Prohibited Substances and Methods', available online at: http://list.wadaama.org/prohibited-all-times/prohibited-substances/.

19 WADA v Jessica Hardy \& United States Anti-Doping Agency (USADA) (CAS 2009/A/1870, 21 May 2010), available online at: http://jurisprudence.tas-cas.org/sites/CaseLaw/Shared\%20Documents/1870.pdf .

20 IAAF v RFEA \& Josephine Onyia (CAS 2009/A/1805; CAS 2009/A/1847, 22 September 2009), available online at: http://www.tas-cas.org/d2wfiles/document/3578/5048/0/Award20180520internet.pdf.

21 See Raphael Sachetat, 'Pregnant Zhou Mi Claims Innocence in Doping Scandal', Badzine (27 October 2011), available online at: http://www.badzine.net/news/pregnant-zhou-protests-innocence-in-dopingscandal/17061. 
Clenbuterol during the Chinese Open in 2010 and strongly protested his innocence, claiming the substance must have been ingested after eating contaminated meat in China. Ovtcharov provided a hair sample as corroboration, and the German Table Tennis Federation chose not to hand down a sanction (a decision WADA never appealed to the CAS). ${ }^{22}$

Alessandro Colo gave a similar explanation regarding contaminated meat in Mexico to explain his positive sample during the last stage of the Vuelta a Mexico in April 2010, which was accepted by the Italian Anti-Doping Authority and merited a reduced one-year suspension. ${ }^{23}$ At the same competition, Dutch cyclist and final stage winner Philip Nielsen tested positive for the substance and blamed contaminated food from a buffet at his hotel in Mexico, causing the Danish Cycling Federation to dismiss the charges against Nielson (WADA later withdrew its appeal to the CAS). ${ }^{24}$ The Mexican Football Federation initially suspended five players who tested positive for Clenbuterol during the Gold Cup in June 2011, but later reversed the suspensions after an investigation by FIFA revealed there was a public health problem in Mexico associated with the use of Clenbuterol in the livestock industry. WADA filed an appeal of the Mexican Football Federation's decision to not suspend the players but withdrew this appeal following the evidence provided by FIFA. ${ }^{25}$ The practice of using Clenbuterol in Mexico was again confirmed by FIFA and accepted by WADA in the under-17 World Cup in 2011, when players from 19 of the 24 teams tested positive for trace amounts of Clenbuterol in 109 of 208 urine samples. ${ }^{26}$

\section{Contador}

Contador, however, is an excellent example of how far matters have gone with the principle of strict liability and how high the burden of proof has become. In Contador, champion cyclist Alberto Contador was subjected to a doping control test during the 2010 Tour de France (an event he subsequently won). Test results revealed that his system contained trace amounts of Clenbuterol (four times lower than Colo, for example, but as discussed any presence of this substance at all gives rise to liability). Contador was provisionally suspended pending verification of the sample and the conduct of a hearing before the anti-doping panel (the Comite

22 Shane Stokes, 'WADA Chief Confirms that Agency Won't Appeal Dimitrij Ovtcharov's Clenbuterol Case Dismissal', Velonation (11 February 2011), available online at: http://www.velonation.com/ News/ID/7408/WADA-chief-confirms-that-Agency-wont-appeal-Dimitrij-Ovtcharovs-Clenbuterol-casedismissal.aspx.

23 Shane Stokes, 'Italian Rider Colo Given Reduced Ban for Clenbuterol Positive', Velonation (9 October 2010), available online at: www.velonation.com/News/ID/5957/Italian -rider-Colo-given-a-reduced-banfor-Clenbuterol-positive.aspx.

24 Cycling News, 'WADA Withdraws Appeal in Nielson Clenbuterol Case', Cycling News (13 October 2011), available online at: http://www.cyclingnews.com/news/wada-withdraws-appeal-in-nielsenClenbuterol-case.

25 Steve Frothington, 'WADA Drops Clenbuterol Case Against Mexican Soccer Players', VeloNews (12 October 2011), available online at: http://velonews.competitor.com/2011/10/news/wada-dropsClenbuterol-case-against-mexican-soccer-players 195167.

26 Associated Press, 'FIFA: U-17 Players' Drug Tests Tainted', ESPN Soccer (17 October 2011), available online at: http://espn.go.com/sports/soccer/news/_id/7115036/Clenbuterol-found-most-players-17world-cup. 


\section{CONTADOR, DOPING AND STRICT LIABILITY}

Nacional de Competicion y Disciplina Deportiva) of the relevant National Federation (the Real Federacion Espanola de Ciclismo).

At the hearing, Contador argued that the presence of the banned substance was explained by his having ingested meat containing the banned anabolic agent. He relied on various reports of anabolic agents having been used in the local cattle industry. The panel accepted this evidence; largely on the basis that it seemed plausible and possible that this could be the case and that in the event the meat was contaminated it would not be at all reasonable to expect the athlete to avoid this. Contador was given a sanction of a one-year ban from the sport, shortened by the time he had already been out of competition.

Both the UCI (International Federation for Cycling) and WADA appealed this result to the CAS. Although a previous attempt to appeal a result of this nature to the CAS had failed for lack of jurisdiction, ${ }^{27}$ Contador had competed in an international event and was covered by the UCI antidoping rules such that there was no issue regarding the CAS' jurisdiction. The CAS panel utilised the opportunity and made important clarifications to the burden of proof the World Anti Doping Code places on an athlete in cases where he or she is relying on exceptional circumstances to escape or reduce any applicable sanction.

In the appeal, the UCI and WADA argued that Contador had failed to meet the burden of proof of establishing the means by which the substance entered his system. The rules provide that it is for the athlete to establish how the substance came to be in his or her system. This requires proof on the standard of balance of probabilities. The CAS panel stated that the athlete's burden could not reasonably be higher than that (as is the case with the prosecution, who are required to establish the commission of an anti-doping violation on the standard of 'comfortable satisfaction'). ${ }^{28}$

In Contador, however, the athlete attempted to raise a number of alternative explanations for the presence of Clenbuterol in his sample. The CAS Panel stated that:

...if, after carefully assessing all the alternative scenarios invoked by one of the parties as to the source of entry of the Prohibited Substance into the Athlete's system, several of the alleged sources are deemed possible, they have to be weighed against one another to determine whether, on balance, the more likely source is the one invoked by the Athlete. However, in the extreme situation that multiple theories were held to be equally probable, the burden of proof, i.e., the risk that a certain fact upon which a party relies cannot be established, would rest with the Athlete.

27 In 2006, two Pakistani cricketers were found to have had Nandrolone (another banned steroid) in their system. An initial hearing before the Pakistan Cricket Board's anti-doping panel resulted in both players being banned. However, on appeal (to an appeal panel established under the Pakistan Cricket Board's anti-doping rules) both were able to escape any sanction by successfully arguing that the presence of the substance was due to contamination of diet supplements or a rigorous training regimen. The attempt to appeal this result to CAS failed for lack of jurisdiction, as the rules of the Pakistani Cricket Board did not provide for appeals to the CAS: see WADA v Pakistan Cricket Board E Akhtar \& Asif (CAS 2006/A/1190, 29 June 2007).

28 This is provided for in article 3.1 of the World Anti-Doping Code. Curiously, this standard can be traced to Australian law: see M Holmes, 'The CAS: A case study of an international arbitration institution' (2005) 27 Australian Bar Review 56. 


\section{CONTADOR, DOPING AND STRICT LIABILITY}

Thus, it is only if the theory put forward by the Athlete is deemed the most likely to have occurred among several scenarios, or if it is the only possible scenario, that the Athlete shall be considered to have established on a balance of probability how the substance entered his system, since in such situations the scenario he is invoking would have met the necessary $51 \%$ chance of it having occurred. ${ }^{29}$

The Panel also clarified the extent to which this affects the burden of proof resting on the antidoping authority:

...the Panel underlines that in light of the jurisprudence of the Swiss Federal Tribunal [the UCI and WADA] do not have the burden of establishing that other alternative scenarios caused the adverse analytical finding, since the risk that the [Athlete's] scenario cannot be ascertained remains with them. The likelihood of alleged alternative scenarios having occurred is, however, to be taken into account when determining whether the Athlete has established, on a balance of probabilities, that the source he is alleging of entry into his system of the Prohibited Substance is the more likely. ${ }^{30}$

Further in the Award, the Panel makes specific reference to Contador's allegation that his test results could be explained by his having ingested contaminated meat:

the Panel notes that [the UCI and WADA] do not argue that the meat contamination theory is totally impossible per se. [They] merely tried to convince the Panel of the very low probability of this theory having occurred and in doing so arguing that Mr Contador did not establish to the relevant standard of proof, i.e. on a balance of probabilities, how the prohibited substance entered his system. ${ }^{31}$

Much of the evidence presented by Contador related to the statistical probability of meat that could be traced to a particular Spanish abattoir being tainted. In its review of the statistical data, the Panel noted that, regardless of how the statistical likelihood of Clenbuterol contamination was calculated (a specific regional abattoir where Contador's meat was likely to have originated, Spain generally, or the EU in total), the likelihood of contamination was virtually nil. Not only did the specific abattoir have no Clenbuterol positive tests, but, as the Panel observed:

even if the Panel ups the scale to an entire region, to Spain or even to all the Member States of the European Union, the statistical chance of a cow being contaminated with Clenbuterol remains very low.

In addition, independently from the various statistics invoked by both parties, the Panel finds it unlikely that in practice a farmer would slaughter any illegally fattened animals shortly after administering the product intended to fatten them.

...the Panel [therefore] agrees with the submissions of UCI and WADA that the possibility of a piece of meat being contaminated in the EU cannot entirely be ruled out, but that the probability

29 Contador award, para 261. It is interesting to note how the Panel defines the balance of probability in pure mathematical terms as requiring the establishment of a $51 \%$ probability, an approach not typically seen in common law decisions. This is perhaps not surprising given that the Panel was composed of three civil lawyers (President of the Panel, Efraim Barak, former Chief Justice of Israel; Ulrich Haas, a Swiss law professor; and Quentin Byrne-Sutton, a Swiss attorney).

30 Contador award, para 263.

31 Contador award, para 317. 
of this occurring is very low. ${ }^{32}$

A further two possible explanations were advanced by Contador: the possibility that he might have received blood tainted with Clenbuterol and the possibility that he might have taken a dietary supplement that was similarly tainted. The Panel was not sufficiently satisfied of the likelihood of either of these explanations to find in favour of the athlete. ${ }^{33}$ An attempt by UCI and WADA to adduce evidence of Contador having 'kept bad company' (he had been involved previously with a number of individuals found to have been involved in doping ${ }^{34}$ was, however, given short shrift by the CAS Panel.

In the absence, therefore, of finding that there was sufficient evidence to satisfy the requirements of WADC 10.5, a sanction of 2 years was imposed. The Panel chose to reserve its decision on costs and the imposition of a fine.

\section{Observations and conclusions}

The Contador case clearly confirms the long-standing practice of the CAS to apply, without question, the concept of strict liability established by WADC 2.1. As with many athletes before him, Contador's attempt to escape sanction by pointing to a variety of alternative theories capable of explaining his adverse test result failed. The Panel confirmed that any such attempt must satisfy the evidentiary burden of being proven on the balance of probabilities. In this respect, the decision shows very clearly the important role CAS plays in establishing and confirming a consistent approach to determining doping cases on the basis of the athlete being burdened with the task of disproving any fault (or significant fault).

An important practical aspect of this case relates to the extreme cost of mounting such a defence. The conduct of the Contador arbitration was much delayed, owing to disputes concerning evidence and pleadings. It is unfortunate that in this respect the CAS procedure appears to have differed little from that obtained in ordinary civil litigation. It is hard to imagine what Contador's legal fees would have amounted to. In addition, given the highly technical nature of Contador's argument, it was necessary for him (and in response for UCI and WADA) to engage

32 Contador award, para 322.

33 The tainted supplement argument has had a long history. Argentinian tennis player Guillermo Coria attempted to rely on this argument when facing sanctions after testing positive to nandrolone (another banned steroid) in 2001. In that case the ATP anti-doping panel determined that even though evidence established that the supplement manufacturer may have caused Coria's supplement to have been tainted, Coria still remained responsible for the presence of the Prohibited Substance in his system. An initial two year ban was reduced to seven month (after taking into account time Coria voluntarily remained out of competition). Coria subsequently sued the company responsible for the manufacture of the supplements he was taking (and endorsed). The lawsuit was settled for an undisclosed amount: see Jeffrey Gold, 'Coria Settles Lawsuit in Steroid Case', USA Today (20 June 2007), available online at: http://www.usatoday.com/sports/tennis/2007-06-20-1620130766 x.htm. Of course Coria's case differs significantly from Contador's in that Coria was able to adduce direct evidence of supplement contamination, unlike Contador. For more on tainted supplements, see the case of Jessica Hardy, above.

34 These were individuals whose culpability was established in the infamous Puerto investigation, which dealt with allegations of systematic doping in Spanish cycling: see Contador award, para 341. 
numerous experts and conduct significant statistical testing and investigation. Again, the cost of this strategy would put it beyond the reach of the ordinary athlete.

One has to wonder whether the anti-doping movement has this time gone too far, whatever one's view of Contador and his argument. The amount of Clenbuterol found in Contador's sample was little more than a trace-hardly enough to constitute performance enhancement (unless it was the residue of a long term course of steroid abuse; and other than Contador's questionable past associations, there was no evidence of this). To be sure, the desire to rid sport of the scourge of doping is based on valid and justifiable concerns. However, when one considers the practical implications of the strict liability principle and the difficulty for the athlete who tests positive to a banned substance where its ingestion was inadvertent to establish his or her lack of culpability, one has to wonder whether the World Anti-Doping Code has gone too far. Placing the burden on the athlete to actively prove there was no fault (or no significant fault), combined with the difficulty and expense of proving the exact cause of contamination when the ingested sample no longer remains, may be shifting the relevant standards away from international human rights.

Given the difficulties in establishing such a defence, if there is any suggestion or concern that meat may be contaminated with Clenbuterol (as there clearly is in China, Mexico, and perhaps even the EU, although that was not proven to the satisfaction of the CAS), then athletes may find themselves having to take far more care in their diet than is already the case. 